\title{
Elaboración de la historia oral en Brasil* El proceso de transición visto a través de las historias de vida de los dirigentes políticos
}

\author{
Aspásia Camargo
}

\section{Legitimidad e ilegitimidad de la historia oral}

A unque la tradición oral es tan antigua como la historia misma, puesto que Herodoto, padre de la historia, se sirvió de ella, perdió popularidad durante el movimiento histórico-positivista del' siglo XIX, mientras adquirían mayor importancia las fuentes que proporcionaban los documentos escritos basados en hechos que podían ser verificados objetivamente por otros historiadores. A partir de entonces, la tradición oral pasó a ser parte de la superstición popular, de fábulas y relatos no convencionales; los historiadores se apartaron de ella y asumieron el papel de indiferentes jueces de los hechos. ${ }^{1}$

Al paso del tiempo, con los adelantos logrados en otras ciencias so: ciales, como antropología, semiología y lingüística, se ha puesto en claro que la palabra del actor social tiene su propia lógica estructurada "como lenguaje" que permite penetrar en el fenómeno social que escapa a la distante y fria observación del historiador y que por medio de una complicidad controlada podremos llegar a comprender mejor el funcionamiento de las instituciones y de la vida social.

Desafortunadamente, la historia como disciplina, en particular en América Latina, no se ha compenetrado con estas nuevas tendencias que la compelen a la interacción con otras ramas del conocimiento. Tal 'vez por miedo de que la historia pierda su identidad, los historiadores se oponen a la "subjetividad" y a las formidables distorsiones que acompañan al discurso oral. Aunque hay investigadores de disciplinas diferentes que personalmente utilizan entrevistas grabadas para obtener datos, persiste la crítica sobre la utilidad y el sentido de la historia oral. Se ha acentuado este prejuicio debido a un cierto matiz de origen que ocasiona que la historia oral se confunda con el ingenuo empirismo que ha reinado, desde su creación, en los Estados Unidos. Además se ha hecho uso de la entrevista grabada como si se tratara de un registro mágico del proceso histórico - confeccionado, pulido y definitivo-, como si la verdad pudiera estar encerrada en un caótico montón de rollos y cintas grabadas sin precisión y sin el rigor inherente al campo de la investigación. Esta tendencia metodológica que se ha infiltrado durante décadas en la historia oral estimuló la resistencia de la comunidad académica latinoamericana e impidió además, que se discutieran con mayor profundidad los verdaderos e inquietantes problemas que resurgen al reevaluar las fuentes orales en diferentes lugares del mundo.

* Este artículo es resultado de una ponencia presentada en la V Conferencia Internacional de Historia Oral llevada a cabo en Barcelona del 29 al 31 de marzo de 1985. Traducción de Concepción Genovés.

1 Paul Thompson, The voice of the Past, Oral History, Oxford University Press, Oxford, Londres, Nueva York, 1978. 
Indudablemente, la aparición de la grabadora situó a la fuente oral en un nuevo status al aumentar su plausibilidad, puesto que la grabación es una reproducción exacta del discurso del actor. De suerte que la dudosa "traducción" del investigador sacada de sus notas de campo ya no era necesaria, y se tornó viable la tan anhelada verificación de los historiadores del siglo XIX. En consecuencia, desaparecieron las principales objeciones al discurso oral y la confiabilidad de la fuente misma estuvo garantizada por lo que hoy conocemos como historia oral.

El segundo paso en importancia era convertir esta técnica de innegables posibilidades y mérito, pero sin utilidad definida, en una fuente histórica equiparable a la escrita. Esto tuvo lugar fuera de los Estados Unidos donde se creó y consagró la técnica; sus agentes fueron historiadores europeos que se identificaron con el acercamiento interdisciplinario y con la historia social en boga, que ha caracterizado a la contribución del continente. Esta corriente encontró eco en los Estados Unidos y en Brasil, aunque la legitimidad de la fuente oral y su técnica continúa siendo cuestionada en las universidades brasileñas.

La historia oral, al pasar de técnica a fuente, está en deuda con los que señalaron las diferencias y semejanzas entre las fuentes escritas y las orales, y también con los que insistieron en su importancia para reconstruir la historia de las clases populares, historia de la que escasamente se trata en las fuentes escritas. ${ }^{2}$ Estas diferencias y semejanzas, a pesar de todo, deben examinarse con todo detalle no sólo en lo que a premisas teóricas se refiere sino a la luz de lecciones producto de la práctica en programas de historia oral. En este trabajo se presentarán varias de estas lecciones.

La crítica y los cargos que se han hecho a la historia oral en los debates sobre el tema, podrían resumirse ${ }^{3}$ en esta forma; 1) a los protagonistas (en sus discursos) les interesa más justificar y elogiar sus obras e intereses que la reconstrucción de la verdad; 2) a diferencia de la fuente escrita, la historia oral es el discurso del día de hoy sobre el pasado, y el presente falsea la reconstrucción del pasado; 3) las inexactitudes, omisiones y la selectividad que caracteriza a la memoria, o impiden o entorpecen la objetividad en la narración. Por razones ideológicas (y fisiológicas) esta clase de fuente es incierta e imprecisa.

Sobre estos argumentos han discutido profesores y estudiantes, conservadores y simpatizantes de la izquierda, legos y eruditos, y todos ellos parecen ignorar el hecho de que la objetividad es, ante todo, obra del investigador y se basa en los preceptos y limitaciones propios de su disciplina. En términos epistemológicos, una fuente oral es tan subjetiva e incompleta como una escrita. ${ }^{4}$

2 Ibid. Véase también Luisa Passerini, "Genealogía della Storia Orale" en Storia Orale, Vita Quotidiana e Cultura Materiale della Classi Subalterne, Torino, Rosenberg \& Sellier, 1978. El primer programa de historia oral que se estableció en América Latina desde este punto de vista, fue el del Instituto Nacional de Antropología e Historia de México, coordinado por Eugenia Meyer, que recopilaba entrevistas con los campesinos sobre el tema de la Revolución mexicana.

${ }^{3}$ Conferencias en el Imperial Museum of Petrópolis (1976), las Universidades de Paraiba (1980), Ceará (1981), la Universidad Federal Fluminense (1977), la Universidad de Bahía (1983), la Universidad de Paraná (1973) y la Universidad de São Paulo-USP (1982), Universidad de Brasilia (1977), Minas Gerais (1983).

4 Aspásia Camargo, “O Ator, o Pesquisador e a História: Impasses Metodológicas na Implantação do CPDOC" en Edson de Oliveira Nunes (organizador) - A A ventura Sociólogica, Rio, Zahar, 1978. Véase también, del mismo autor. "Historia Oral: Técnica 
Es ahora el momento de discutir aquí la necesidad de considerar la historia oral como un conjunto de testimonios integrados y complementarios, representativos del universo en cuestión. Así pues, no se trata de una declaración aislada. Esta observación nos lleva a sugerir "el uso sistemático de los hechos entrecruzados y los juicios superpuestos que pueden reconciliar la comprensión (verstehen) del testimonio oral con la confiabilidad que generalmente se atribuye a los documentos escritos. Para terminar, "esto sería una clave metodológica conveniente para delimitar la subjetividad inevitable de cada narración en relación al principio de que relatos ideológicamente diferentes tienden a neutralizarse entre si".'s Asi mismo, la técnica de la bola de nieve que recomienda Bertaux, propone un límite numérico ideal para la serie de entrevistas que se van a presentar. ${ }^{6}$

A pesar de los progresos alcanzados hasta ahora, aún no se han disipado las dudas que predominan en la comunidad científica. Estas sólo desaparecerán cuando en el desarrollo de esta historia oral que todavia se utiliza e interpreta de acuerdo con el criterio individual, cuando se normen las técnicas y los procedimientos que dependen todavia del criterio de cada investigador. Esta búsqueda de identidad que, por el momento, se limita (en el mejor de los casos) a colocar la fuente oral en el mismo nivel de la escrita, puede hacer que la historia oral que ahora asume una actitud defensiva, se convierta en ofensiva. Esto nos lleva a determinar cuáles son los aspectos que hacen que la fuente oral sea original y cuáles revelan su contribución específica.

El establecimiento del programa de historia oral CPDOC en la Fundación Getulio Vargas y el progreso en los estudios de investigación ahí realizados nos permiten destacar ciertas características especiales de la fuente oral y ocuparnos además de otras que merecen mavor atención. En primer lugar, la historia oral es una fuerza "totalizadora" compuesta por documentos que se complementan y entrelazan, proporcionando el panorama de un todo (por medio de un sólo testimonio o por una serie de ellos) que es virtualmente inasequible cuando se utilizan fuentes escritas. Lo cual quiere decir que con la historia oral disminuyen los riesgos de fragmentación del conocimiento inherente al proceso normal de división del trabajo y del desarrollo de la investigación cientifica.

En segundo lugar, este efecto totalizador surge de una manera singular por medio de la confrontación entre la experiencia concreta de la vida y la información obtenida por el investigador-entrevistador, quien sirve de elemento ordenador de los resultados obtenidos. Esto proporciona a la fuente oral una compatibilidad resultante de su carácter inducido, a diferencia de otras fuentes espontáneas y erráticas.

En tercer lugar, cuando se utiliza el método de la historia de vida, como veremos, la información de los actores no sólo se presenta como una ideología sino como una práxis al mismo tiempo; esto es, como un testimonio dinámico de la realidad social en movimiento. Así pues, por medio de esta fuente se pueden transferir conflictos, contradicciones,

e Fonte Histórica", en la introducción al Programa de História Oral. Catálogo de Depoimentos, Rio, CPDOC, Fundación Getulio Vargas, 1981.

5 Aspásia Camargo (coordinador), Eduardo Raposo, Sergio Flaksman, $O$ Nordeste e a Política: Diálogo com José Américo de Almeida, Río, p. 4, Nova Fronteira, 1984.

- Daniel Bertaux, "From the Life History Approach to the Iransformation of Sociological Practice" en Bertaux (ed.) Biography and Society: The Life History Approach in the Social Sciences, Londres, Sage, 1981. 
prácticas y valores articulados sincrónica y diacrónicamente. Más que la reconstrucción de los hechos, el investigador deberá recapturar la lógica del funcionamiento y los cambios en la estructura social.

\section{El programa CPDOC: documentación e investigación.}

En 1975 CPDOC inició un programa de entrevistas a dirigentes políticos activos desde la revolución de 1930 en adelante, quienes dieron origen al periodo conocido como la era de Vargas. En un principio, el propósito fue establecer un banco de datos permanente y al día. Secuencias históricas renovables que constituyen hoy una reserva de alrededor de 2000 horas grabadas en más de doscientas entrevistas, enriquecen la reserva de ese periodo reciente. Otro objetivo, en este caso velado, era romper la barrera impuesta durante tanto tiempo por el régimen militar autoritario que comenzó en marzo de 1964 y que terminaría el 15 de marzo de 1985. La realidad es que el régimen militar borró de la memoria los recuerdos del periodo populista que lo precedió, exactamente igual que los populistas habían borrado los recuerdos del periodo autoritario del que a su vez habian surgido. Escuchar "la voz del pasado" era, al parecer, el medio más efectivo para comprender y transformar un doloroso y problemático presente.

Con las dos entrevistas iniciales salió a la luz una cantidad considerable de información complementaria relacionada con la revolución de 1930 y con sus orígenes. Estos testimonios que desde entonces se han ido publicando, ayudaron a develar la lógica de la historia de Brasil durante seis décadas ${ }^{7}$ estableciendo las conexiones entre el florianismo, militarismo populista que acabó con la república (1889), el reformista tenentismo de los oficiales militares jóvenes (1920-30) y el régimen conservador corporativo de los años 60 y de $\operatorname{los} 70$, que se ha liquidado ahora. Este canal -entre otros que nos proporcionaron las entrevistas - reveló de inmediato la importancia de realizar entrevistas más largas, con un plan abierto y flexible como instrumento para generar hipótesis en el campo de la sociología histórica, debido a la natural cercania que se establece entre el presente y el pasado.

Con estas entrevistas también se confirmó la importancia de "totalizar" fuentes en este tipo de estudios, sin olvidar el universo de acción y de reflexión, vasto y sin referencias, de los sujetos entrevistados. En países como Brasil, donde la documentación está desorganizada y la historiografía es aún incipente, es mucho más importante el papel que desempeña la fuente oral. Lo que queremos dejar sentado aquí es que cuando el historiador contemporáneo se enfrenta a un continente extenso e inexplorado - donde la fuente de información escrita no existe o es inaccesible o fragmentada - la historia oral puede ser una contribución de incalculable valor.

El papel pionero de la historia oral también se definió durante el Programa de la Historia Oral de la Ciencia, en Brasil. La riqueza de infor-

${ }^{7}$ Las dos primeras entrevistas clave se hicieron a José Américo y à Osvaldo Cordeiro de Farias, la primera en un libro ya citado, y la segunda aparece en Aspásia Camargo, Walder de Goes, Meio Século de Combate: Diálogo com Cordeiro de Farias, Río, Nova Fronteira, 1981. Las demás entrevistas publicadas fueron las que se hicieron con Juracy Magalhães; Alzira Abreu (coordinador), Eduardo Raposo, Paulo Farah. Minhas Memórias Provisórias; Civilização Brasileira, 1982, Aspásia Camargo (coordinảdor), O Intelectual e o Político: Encontros com Afonso Arinos, Brasilia,'Senado Federal - Dom Quixote Ed., 1984. 
mación que se obtuvo sobre este campo olvidado llegó mucho más allá de las limitaciones de un primer libro basado en las entrevistas que se realizaron para este propósito. ${ }^{8}$ Otros estudios sobre historia regional, partidos políticos y tenentismo se basaron también en la materia prima obtenida de una serie de entrevistas de historias de vida. ${ }^{9}$

En resumen, la característica "totalizadora" de la fuente oral se manifiesta en su condición complementadora: la oposición y articulación de lo que puede denominarse continuidades temáticas. La angustia del cronometraje y la dimensión del proceso hacen posible el esclarecimiento del origen políticosocial de los fenómenos históricos y de los lazos que existen entre ellos. Por esta razón, en lugar de reconstruir la historia "oficial" de las elites o la aterradora "apologia de grandes hombres", logramos obtener una reconstrucción amplia de estructuras en movimiento durante un periodo de transición estratégicamente decisivo. Además, conseguimos recrear una historia social de la politica.

Se puede afirmar a posteriori, que el programa de CPDOC sirvió para unificar dos tradiciones opuestas: la norteamericana y la europea; la primera pone de relieve una concepción de la historia oral como banco de datos cuyo deber público es socializar la información recibida para uso de la comunidad académica; la segunda incorpora la lógica de la investigación científica en la inducción, procesamiento y empleo de los datos creados según la iniciativa del investigador. Aquí, la interacción entre la documentación y la investigación es constante.

Como parte integral del sector de investigación del CPDOC, la historia oral contó con la participación del equipo de investigación y con estudios monográficos que se habian realizado sobre el periodo. Así mismo, los estudios se beneficiaron directamente con los datos proporcionados por las entrevistas. Investigadores ajenos al CPDOC experimentaron también sobre este mismo proceso. A pesar de la enorme inversión que requiere montar un banco de datos, podemos afirmar que, en la actualidad, la información rescatada rinde valiosos servicios a los investigadores, quienes, a cambio, nos proporcionan la información debidamente procesada, y comparada con fuentes distintas a las entrevistas complementarias que realizan por iniciativa propia, y que generalmente se almacenan en la sección de Historia Oral del CPDOC.

\section{Proceso de transición: fuentes orales y escritas}

Durante los últimos años, investigadores del CPDOC se han dedicado a procesar el material obtenido, bien por medio de estudios de investigación y de tesis o bien por publicaciones de los textos completos de las entrevistas. Los dos libros adicionales, ya casi terminados y que contienen las entrevistas, atestiguan el valor del intercambio entre las fuentes orales y las escritas en la exposición de los procesos actuales de transición. ${ }^{10}$ Como es natural, las sesiones de entrevistas iban invariablemente precedidas por una cuidadosa investigación de las fuentes documen-

8 Véase História da Ciéncia no Brasil: Catálogo de Depoimentos, Simon Schwartzman (coordinador), FINEP / CPDOC, 1984. Del mismo autor: A Formação da Comunidade Cientifica no Brasil, Rio, FINEP, 1979.

- Véase María Cecília Spina Forjaz, tesis - Tenentismo e Forçãs Armadas na Revolução de 1930, São Paulo, Ph. D., USP, 1982.

10 Las entrevistas en preparación son: $O$ Empresário na Política: Diálogo com Clemente Mariani y $O$ Partido e o Poder: Diálogo com Amaral Peixoto que es un panorama general de la politica brasileña. 
tales de que se disponia, depositadas, en gran parte, en la sección de archivo de CPDOC.

También se contaba, para las entrevistas más significativas, con documentación oral complementaria proporcionada por "informantes competentes" quienes conocían bien la trayectoria de la persona a la que se iba a entrevistar. Naturalmente que no se podía corroborar de inmediato gran parte de la información obtenida, y menos aún de la escrita. En estos casos, después de terminada la entrevista se recurría a las fuentes escritas y a los archivos privados; esta era la segunda etapa de la investigación durante la fase de preparación del libro. En la práctica esta confrontación a posteriori se utilizaba para invalidar la estereotipia según la cual las fuentes orales son inexactas y engañosas y las escritas objetivas y confiables.

En general, quedó bien claro que las dos fuentes, aunque de características diferentes, tendían a moverse en la misma dirección, si bien la información obtenida en los archivos era más precisa, fragmentada y detallada, y la historia oral era más totalizadora e impresionista. Las evaluaciones eran complementarias y reciprocamente esclarecedoras, sin que una excluyera a la otra. Cuando nuestras preguntas eran embarazosas o cruciales, el protagonista prefería no contestar en lugar de mentir. En muchas ocasiones, los protagonistas se encargaban de esclarecer, añadir y confirmar información cuestionable, tornándola convincente y fidedigna.

Un proyecto reciente basado en la historia de vida del mariscal José Pessoa dio lugar a los comentarios de un historiador del ejército, en el sentido de que las fuentes escritas corresponden a los "planos cartográficos" de una operación de guerra, mientras que las fuentes orales son como "la realidad de la lucha misma", que obligan al proyectista a reajustar las decisiones previas."

Es evidente que en ocasiones, las diferentes evaluaciones proceden de actitudes diferentes ante el campo en conflicto, y que estas divergencias ayudan a develar la lógica que rige las oposiciones y las alianzas, y la causa y naturaleza del conflicto político. Además, las aparentes contradicciones entre el discurso oral del presente y las fuentes del pasado dan origen a una apertura para revisar cuestiones históricamente ambiguas y oscuras, en lugar de ser pruebas de la "inferioridad natural" del discurso oral, en comparación con el documento escrito. En las dos tesis recientes que ya hemos mencionado, la fuente oral fue el detonador de la investigación, que se elaboró, completó y comparó, durante una segunda fase, con las fuentes escritas.

Mientras que en el nivel del microanálisis la historia oral pasó el examen de veracidad, en el nivel del macroanálisis se advirtió en el discurso oral una capacidad de sintetizar un vasto periodo politicosocial con sorprendente economia de recursos; nos proporcionó un panorama sin precedentes del proceso de transición de una sociedad política tradicional, en su lucha contra los dramas y conflictos que impone la época moderna. Por ejemplo, la evolución del regionalismo como fuerza motor de la política, en sentido estricto, destacó en forma panorámica, llena de riqueza y muy convincente; la fragilidad del sistema de parti-

"Evaluación hecha por el biógrafo de José Pessoa, Lt. Cel Hiram Camara, quien utilizó fuentes escritas y orales para preparar su trabajo.

En el primer bosquejo sólo se utilizaron informes tomados del archivo, decretos que se completaron con entrevistas de historia oral compiladas para el proyecto "Marshall José Pessoa". 
dos políticos y la articulación de intereses dentro del proceso político descrito, así como el papel del "personalismo" fueron las diferentes etapas de consolidación del Estado. En este contexto, quedó explícita la importancia de lo que llamamos actores clave; esto es, la de nuestros protagonistas como individuos dotados de recursos políticos propios. Evidentemente, han sido utilizados como sustitutos funcionales, durante décadas, por instituciones crónicamente débiles.

Finalmente, pudimos descifrar la clave de estos conflictos sucesivos recurriendo a un personaje central, Getulio Vargas, sobre el cual todos los actores hablaron con espontaneidad. Vargas acumuló a su alrededor los mayores conflictos de la época: la oposición entre la agricultura y la industria; entre un liberalismo-conservador y un populismo autoritario-reformista; entre un partidismo extranjerizante y un nacionalismo; en breve, entre democracia sin progreso social y progreso social sin democracia. Por diferentes relatos salieron a luz conflictos y paradojas, lo cual nos permitió captar mejor la verdad de lo que decía cada uno de los actores. Fuimos testigos del drama de una modernización manifiesta que, originada por ideologias y yendo mucho más allá, aún no alcanza el éxito final. ${ }^{12}$

\section{Bases metodologicas: historia oral e historia de vida}

En un principio planeamos utilizar al actor como base de las decisiones, estructuras y procesos más bien que para reconstruir acontecimientos de duración limitada y de menor alcance. En lugar de realizar una serie de entrevistas fragmentadas sobre diversos acontecimientos, intuitivamente, preferimos hacer entrevistas largas a un sólo sujeto, que servirian de enlace con las de los otros, en una sucesión conjunta de acontecimientos ("continuidades temáticas").

Debido al reducido número y baja rotación de nuestras elites, esta forma de trabajar significaba en realidad, la reconstrucción de la experiencia social de los actores que han dirigido el escenario político durante las seis décadas pasadas. Así, el método de historia de vida surgió como el medio ideal para aprovechar al máximo ese principio de totalidad que, como hemos visto, eleva al máximo las potencialidades de la fuente oral. ${ }^{13} \mathrm{La}$ actitud del actor saliente de su posición en la historia garantizaba que su relato sería un elemento significativo en la estructura misma.

Subsecuentemente, de las historias de vida surgirian otras notables ventajas. Técnicamente facilitaban el acercamiento inicial para la entrevista, estimulando la complicidad y comprensión entre entrevistador y sujeto, antes de introducir temas polémicos. Además, permitía que los acontecimientos narrados se ordenaran jerárquicamente de acuerdo con la lógica del participante, la cual contrastaba a menudo con la ideología del historiador o con la historiografía incipiente. Ciertos acontecimientos como el de la "Constitución de 1934" y la segunda

12 Los relatos de Afonso Arinos y Clemente Mariani, quienes eran enemigos históricos de Getulio Vargas, complementadas con los relatos de Cordeiro Farias, José Américo y Juracy Magalhães, que fueron en diferentes ocasiones grandes colaboradores y decisivos opositores de Vargas. Finalmente, existe un relato pro-Vargas de Ernani do Amaral Peixoto. Sin embargo, estos relatos diferentes coinciden en varios puntos.

13 Luisa Passerini, op. cit., resalta la importancia del principio de totalidad, mientras que Franco Ferrarotti defiende el significado de la dialéctica en los análisis de historias de vida: "On the Autonomy of the Biographical Method", Bertaux op. cit. 
guerra mundial adquirian una inesperada significación sociológica, mientras que otros como el "Tercer Club de Octubre" que sirvió de unión a los revolucionarios de 1930, dejó al descubierto su cuestionabilidad en tanto que acontecimiento político. En breve, en lugar de servir de tema - elemento de orden del discurso histórico- el acontecimiento șe convirtió en uno de los objetos que había que ordenar.

La historia de vida era un medio práctico y seguro para acercar al actor $y$ al investigador a la objetividad deseada. Y ello "por medio del descubrimiento de que la tierra es más fértil, segura y pródiga cuando el discurso del hombre se refiere a lo que mejor conoce: su propia vida". ${ }^{14}$ En este sentido, la objetividad implica el restablecimiento de la temporalidad del hecho social respecto al organicismo de la información recibida, cuyo eje natural es el propio actor en vez de algo artificial que le es ajeno. El organicismo de la información facilita también el control de los hechos recibidos, hechos que pueden verificarse al ser articulados ante el investigador; algo así como juntar las piezas de un rompecabezas. Cuando surge alguna discrepancia en el contexto de una historia de vida en particular; tal discrepancia es el detonador para realizar nuevas averiguaciones que conduzcan a descubrir el significado del hecho, lo que se justifica para satisfacción de las representaciones e ideologías. Finalmente, la historia de vida favorece una casi perfecta articulación. entre el nivel diacrónico y el sincronico; es decir, entre la descripción de las narraciones sociales y el proceso que gradualmente hace que se vayan transformando o no al transcurrir el tiempo. Sin embargo, ambos niveles se ponen de manifiesto en los tópicos de una sola biografía o de los de una serie de ellas.

Otro valioso recurso metodológico que amplía las potencialidades de los documentos orales es el acercamiento interdisciplinario como medio de recapturación del principio de totalidad que está presente en los fenómenos sociales. Cuando es posible, tratamos de reconstruir, desde un punto de vista antropológico, detalles de la vida escolar y familiar; de la red de relaciones sociales de grupos y subculturas; de las complicidades y hábitos en la vida cotidiana de la política del actor.

A través de la historia nos llega la antigua práctica de la reconstrucción del ¿quién? ¿dónde? ¿por qué? ¿cuándọ?; esto es, la descripción de fechas y momento de personas (agentes sociales correlacionados) $y$ hechos de entre los cuales podamos discernir cuál es único y cuál repetitivo en las vidas de los hombres. Hoy en día, estos elementos nos proporcionan la reconstrucción de los personajes notorios y de los hechos de las seis últimas décadas, gracias a la intersección de las historias de vida.

El perfil de los liderazgos principales proviene de un conjunto de relatos espontáneos, consecuencia de una recomposición sorprendentemente detallada de personajes de gran significación histórica, como el líder nororiental José Américo de Almeida. Este material, proporcionado por terceras personas, sirvió de contrapunto a su propia narración y se anexó y analizó al libro que contiene las entrevistas que se le hicieron. ${ }^{15}$ Una consecuencia de este estudio fue que se realizara una confrontación triangular entre los relatos en primera persona y en tercera, que el investigador recibió, corrigió y enriqueció con información de archivo. Los informes sobre Vargas contribuyeron a realizar un es-

14 CPDOC - Catálogo de Historia Oral.

is Op. cit., introducción de Aspásia Camargo, p. 13. 
tudio de su carismática carrera y de varios actos arbitrarios que llevó a cabo durante su vida. ${ }^{16}$ Se está realizando una investigación con el propósito de recrear los grandes momentos de su actuación política, haciendo uso exclusivo de los relatos de las entrevistas. ${ }^{17}$ En estos estudios se confirma una vez más que las omisiones de un informante aparecen oportunamente compensadas en las declaraciones de otros. ${ }^{18}$

Las ciencias políticas y la sociología han tenido gran influencia en el contenido de las entrevistas, sugiriendo preguntas relacionadas con las instituciones y con el ejercicio del partido político, con el proceso electoral y la toma de decisiones del sistema; y también indagando los origenes sociales, socialización, conflictos entre generaciones, regiones, etc. El lento cronometraje del psicoanálisis, con las adaptaciones adecuadas, sirvió de guía a la corriente narrativa de la historia de vida. Entrevistas cronológicamente estructuradas estaban salpicadas de espontáneas incursiones al pasado, siguiendo una lógica propia. Así Riobalde, personaje de un clásico de Guimarães Rosa, advierte:

En nuestra vida están almacenados los recuerdos en diferentes secciones, cada cual con su letrero y sentimiento, algunas, creo yo, no se mezclan entre sí. Sólo relatamos de principio a fin y perfectamente organizadas cosas de poca importancia. Esa es la forma en que pienso, la forma en que hablo. Existen momentos del pasado lejano que permanecen mucho más cerca de nosotros que otros ocurridos recientemente. ${ }^{19}$

O bien, como nos dice Borges: "la memoria, en gran parte, está hecha de olvido".20

Bertaux y Dentzin han insistido, con mucha razón, en que la literatura ha contribuido más a la reconstrucción y comprensión de la vida de la sociedad que las asi llamadas disciplinas científicas. ${ }^{21}$ Así como es cierto que los historiadores han rechazado la información oral por temor a su carga emocional, no puede decirse lo mismo de los grandes autores clásicos que perviven a través de los siglos. La sustancia dramática de la tragedia griega reside precisamente en su audacia para confrontar en el mismo escenario diferentes versiones de personajes, cada uno de ellos ante una absoluta e inexorable verdad. Miles de años más tarde, William Faulkner y García Márquez trataron de encontrar lo relativo de la verdad siguiendo el mismo proceso. ${ }^{22}$

16. Aspásia Camargo, "Charisma and Political Personality: Vargas, from Conciliation to Machiavellianism", LASA, ciudad de México, octubre, 1983.

17 Valentina da Rocha Lima (coordinadora) Getúlio, CPDOC, 1985.

18 Relatos grabados sobre la crisis de los años 50 que culminó con el suicidio de Vargas y sobre los golpes y contragolpes de 1955 son el mejor ejemplo junto con la reconstrucción dèl golpe de $193 \overline{7}$ con el que Vargas inició su periodo' dictatorial.

19 João Guimarães Rosa, Grande Sertão: Veredas, Río, 1984 (16a ed.) p. 92.

20 Jorge Luis Borges, "El Tiempo", en Borges, Oral, Buenos Aires, Emecé Editora Editorial Belgrano, 1982,p. 86.

${ }_{21}$ Bertaux, op. cit., y Norman K. Dentzin, "Interpretando as Vidas das Pessoas Comuns: Sartre, Heidegger e Faulkner", Dados, Social Sciences Review, Rio, IUPERJEditora Campus, vol. 27, núm. 1, 1984.

${ }_{22}$ William Faulkner, The Sound and the Fury y Gabriel García Márquez, Crónica de una Muerte Anunciada. 